\title{
Computer games: Paradigms of opportunity
}

\author{
DAVID B. PORTER \\ United States Air Force Academy, Colorado
}

\begin{abstract}
Computer games offer unique opportunities to apply unobtrusive constraints to action that permit meaningful analysis without destroying the integrity of the game itself. To a much greater extent than most traditional laboratory tasks, computer games represent holistic, meaningful, and natural human activity. Considerable concern about the appropriate analysis and interpretation of results, however, remains. One strategy that addresses these concerns involves the adoption of separate but convergent analytic perspectives. This article suggests that three such perspectives (viz., the objective, the subjective, and the empirical) can be combined to provide the necessary logical leverage to allow meaningful research. Alternative analyses of data collected from the playing of a particular arcadetype computer game are used to illustrate this point.
\end{abstract}

Games are among the most natural of human activities. Although they usually begin as simple amusement or entertainment, they frequently become more elaborate with use, and often increase in significance. Games have rules and boundaries, but within these constraints, participants are likely to contend with one another (or with nature) to the full extent of their abilities. The adaptive significance of games is reflected by their extraordinary persistence and ubiquity among human cultures. Games develop specific skills and perspectives in their participants. Such skills are not without purpose: mental schemata, as well as physical abilities acquired from game playing, often transfer directly to real-life activities (Broadbent, 1986; Piaget, 1969/1970). Game playing can also enhance both individual interpersonal interaction and group effectiveness (Cohen, Fink, Gadon, \& Willits, 1980). In most substantive games, individual choices, skill of execution, and chance interact to determine the eventual outcome. It is curious that a science devoted to the study of human behavior and mental activity has not made better use of natural human games. Although in the last decade well over a thousand articles have been published in the psychological literature that purport to reflect games research, closer examination reveals that many of these "games" have been so simplified and constrained that they bear only superficial similarity to the kind of activities humans undertake for their own amusement.

Admittedly games contain many characteristics that conflict with many standard practices of traditional psychological laboratories. Game activities often happen too quickly to allow accurate objective measurement to be made. Further, the rules that underlie winning strategies for many games often depend on complex contingencies that are often not accessible even to the most accomplished players, let alone to their naive, but objective, psycho-

Correspondence should be addressed to D. B. Porter, Department of Behavioral Sciences, United States Air Force Academy, USAF Academy, CO 80840-6228 (e-mail: porterdb\%dfbl\%usafa@pcmail2.usafa.af.mil). logical observers. Worse yet, games are "messy"-subjects are likely to get excited, and in the process introduce a whole host of confounding exogenous variables, such as motivation and individual skill. The development by Hermann Ebbinghaus (1850-1909) of "nonsense material" is often credited with "emancipating psychology from philosophy" (Hergenhahn \& Olson, 1993). By creating and employing stimuli intentionally devoid of meaning, Ebbinghaus was able to isolate and more systematically examine human learning and memory processes. Unfortunately, Ebbinghaus's approach became an empirical template. Although few experimenters still depend on nonsense materials per se, the tradition of intentionally obscuring the meaning or purpose of stimuli or procedures from subjects continues to be a common characteristic of many contemporary psychological experiments.

Following the general experimental strategy of "simplify and observe," a great deal of information about human information processing has been collected over the last century through the use of exceedingly simple stimuli and tasks (Mook, 1982). However, the general strategies of isolation and simplification of tasks to enhance experimental control and internal validity have not been without cost. The Gestalt psychologists of the early twentieth century argued vigorously that when it comes to human mental activity, the whole is much more than the sum of its parts. They argued convincingly that separating perceptual and problem-solving activities from meaningful contexts greatly limited the general applicability of findings (Wertheimer, 1959). More recently, the work of J. J. Gibson (1962) further emphasized the necessity of individual activity and engagement as a prerequisite for external or "ecological" validity.

Nonetheless, psychological researchers have been slow to adjust their practices. (In contrast, subjects seem to have adjusted quite naturally, by converting even the most meaningless laboratory tasks into their own idiosyncratic "games," thus confounding both psychological researchers and their data.) Variability in individual skill, the persistent improvement created by practice at substantive tasks, 
and the largely unpredictable influence of motivational fluctuations have combined to continue to limit the use of real games as experimental tasks. Broadbent's (1977) work with semicomplex, computer-implemented, dynamic control tasks was one of several early attempts to harness the emerging capability provided by computers to redress the imbalance in research strategy. By carefully controlling internal game contingencies, Broadbent was able to identify particular game strategies and also to show how strategies implied by regularities in subjects' game choices differed significantly from their subsequent verbal accounts (Broadbent, Fitzgerald, \& Broadbent, 1986).

Building on the foundation Broadbent provided, Porter (1986) developed an arcade-type video game specifically designed to examine intermediate cognitive processes. A full account of the findings from these experiments and their theoretical significance can be found elsewhere (Porter, 1991); the purpose of the present article is to identify the general strategy that allowed the identification and verification of the results. It is, however, necessary to describe the game before relating the various forms of analysis that were used.

\section{THE GAME}

The game was entitled Save the Whale. The subjects controlled the direction of movement of a blue whale by using four discrete keyboard inputs. The whale turned in the direction of the last key a subject had depressed and moved one space (the screen was actually a $22 \times 32$ space grid) once every $500 \mathrm{msec}$. Eighteen white icebergs were distributed over the cyan monitor screen. The whale could not stop, move diagonally, or cross the screen border; moving through a space occupied by an iceberg caused the iceberg to disappear. Players scored points by maneuvering the whale either to "eat" plankton or to destroy kayaks by causing them to crash into icebergs, but the number of points allotted to these two tasks varied from one trial to the next. On one third of the trials, the subjects earned 100 points for each bite of plankton; kayak crashes were only worth 10 points. For another one third of the trials, the scoring was reversed, such that plankton was worth only 10 points and kayaks were worth 100 points. On the remaining trials, the two tasks were allotted equal points. The substantive differences between the two game tasks (i.e., eating plankton and wrecking kayaks) require elaboration.

The plankton task was simple but uncertain. A small green mass of plankton moved randomly across the screen from left to right. Although the plankton's general path was somewhat similar from one trial to the next, its precise path constantly varied. Basically, plankton eating was a random tracking task; it was relatively simple to comprehend, but successful performance required practice, patience, and concentration. In contrast, the kayak task was complex but entirely predictable. Red kayaks appeared at fixed intervals from five discrete locations at the screen border; a total of 25 kayaks appeared during each 3-min trial. Once on the screen, kayaks followed a single simple rule: they moved toward the whale. Kayaks remained on the screen until one of two things happened: (1) they encountered an iceberg and crashed; or (2) they reached the whale and harpooned it. The player earned points for each kayak that crashed, but lost an equal number of points for each kayak that harpooned the whale. Unlike real life, the game continued regardless of the number of times the whale was harpooned. Explicit instructions displayed at the beginning of each trial advised the subjects of the number of points allotted to each task throughout the duration of the trial. Distinct priority conditions were presented in a systematic order (e.g., plankton, both, kayak, plankton, both, kayak, etc.), that was counterbalanced across subjects.

\section{ALTERNATIVE PERSPECTIVES AND ANALYSES}

The game allowed the subjects a great deal of apparent autonomy of action. They easily learned to perform the tasks well enough to make the game interesting, but rarely were they able to perform it perfectly (only three of the 2,188 trials contained in the original five experiments were performed near the optimal level; Porter, 1991). The problem of meaningful measurement and appropriate analysis of data followed a general strategy of "surround and conquer." By assuming three distinctively different perspectives, convergent support for several somewhat counterintuitive hypotheses was developed. The three distinctive perspectives adopted were the objective, the subjective, and the empirical. Several analyses from each perspective will be described below. The strongest support, however, was to be found in the comparison of analyses from different perspectives.

\section{The Objective Perspective}

Analysis and understanding of experimental tasks has long been considered an essential prerequisite to systematic inquiry, both in experimental cognitive psychology (Eysenck, 1984) and in human factors (Wickens, 1992). One of the greatest obstacles to the use of computer games in psychology, however, has been the lack of an a priori understanding of the actual logic and contingencies inherent in the games themselves. Some games, such as Orcs and Hobbits, are sufficiently simple and involve choices that are sufficiently discrete (i.e., there are only 14 possible conditions) to allow meaningful observation, manual tabulation, and logical analysis (Thomas, 1974). However, games of skill that involve continuous movement of multiple characters are much more complex, and actions occur so quickly that manual recording of responses would be both meaningless and impossible. Even a simple arcade game such as Save the Whale requires the subjects to make one of four directional choices on each of 250 game "cycles" that were typically accomplished within a 3-min period. Perhaps even more problematic was the fact that the individual moves themselves are relatively meaningless without information concern- 
ing the relative position of other game characters and the particular priority conditions. Ultimately, turning the whale "up" had no greater effectiveness than turning it "left," "right," or "down." A comprehensive (algorithmic) approach to recording all of the hundreds of thousands of potential discrete game events would clearly discourage even the most ardent experimenter.

However, by adopting a perspective from inside the computer (similar to that of John Searle's [1980] infamous man in the Chinese room), regression analysis could be used to make sense out of the subjects' inputs and the game's outcome. In cases in which behavioral phenomena are more variable, putative causes more obscure, and effects more subtle, theories of action must be developed from passive observation. The potency of such analyses can be enhanced greatly if one is able to posit certain logical, hierarchical relationships among variables. Originally developed by Wright (1921), path analysis combines standard regression techniques with assumptions about causation (in the present case, the task structure is the causative factor). (See Cohen \& Cohen, 1983; and Nie, Hull, Jenkins, Steinbrenner, \& Bent, 1975.) The notion that human tasks can be conceived of as hierarchical endeavors is not new. For example, Kenneth J. W. Craik's (1943) resurrection of William James's functionalist concepts clearly emphasized hierarchical control. Broadbent (1971) formally proposed information-processing mechanisms at two distinct levels, and Reason (1984) offered a similar hierarchical formulation for understanding the performance of everyday tasks.

In the case of Save the Whale, this approach was applied in several phases. Task accomplishment (the number of kayaks that crashed and number of times that plankton was eaten) was assumed to be the consequence of specific game behaviors. Initially, an effort was made to measure a wide range of game behaviors (e.g., the number of times the whale changed direction, the absolute location of the whale with respect to each of eight geographical areas, the proximity of the whale to the plankton, the relative efficiency with which the whale turned toward the plankton, the number of icebergs eaten by the whale, the amount of time the whale spent proceeding directly toward [or directly away from] each of the kayaks, etc.). In all, frequency data were collected in nearly 20 discrete categories across the 250 cycles in each game. Measures were then logically assigned to one of three hierarchical categories (viz., strategic, tactical, or mechanical). Strategic actions involved subjects' choice of which task to accomplish; tactical activities involved the rules that described how the selected task was accomplished; and the mechanical-level measures reflected how well strategic and tactical choices were implemented (i.e., in terms of pace and timing).

At the conclusion of a series of five experiments, raw data from 2,188 trials (collected from 108 subjects across all priority, practice, and experimental conditions) were combined. Systematic hierarchical regression analysis was used to construct a performance-path structure that used strategic, tactical, and mechanical variables. Vari- ables for the strategic and mechanical level were the same for both tasks, but distinctive tactical measures were selected for each of the respective tasks. Overall, the explanatory power of the model that was derived was exceptionally good. For plankton eating, three independent variables (one strategic, one tactical, and one mechanical) combined to explain $87 \%$ of the total variance in performance across trials. For the kayak task, three variables combined to explain $58 \%$ of the total variance in performance (Porter, 1986).

A subsequent test from the same objective perspective provided convergent support for the propriety of the path structure that was derived statistically. The frequency counts of activity and the relation of these activities to game outcomes suggested certain rules that subjects used to play the game. A BASIC program incorporating these rules in the hierarchical logic structure assumed by the path analysis was developed and tested with the game. The plankton task required only a single BASIC procedure; in contrast, the kayak task required a series of five separate procedures, each with distinct inputs and actions. Many of the characteristics observed when human subjects played the game were also reflected in the program's play. As it turned out, timing was an extremely important parameter; by gradually increasing the program's speed of processing relative to the game pace, a respectable simulation of the effects of practice was achieved (Porter, 1986). Successful simulation thus served to corroborate the previous statistical analysis, and increased confidence that the rules involved were reasonable approximations of the ones subjects employed to achieve success.

\section{The Subjective Perspective}

The second perspective is that of the subjects. Subjects' introspective accounts of internal mental processes were among the earliest psychological techniques; introspection was employed before the turn of the century by both Wilhelm Wundt (1832-1920) and Edward Tichener (1867-1927). However, John B. Watson's (1913) stinging condemnation of the practice of introspection as "no essential part of psychology" served to impede its subsequent use greatly. With the advent of cognitive psychology and the information-processing approach, introspection has again become a tolerable experimental procedure, but with many caveats and concerns (Ericsson \& Simon, 1984).

Subjective reports provided two types of useful information. The first consisted of the subjects' views and assumptions about the game itself; the second comprised their inferences about the most appropriate rules to follow in successfully accomplishing the respective tasks. At the conclusion of several experiments, the subjects were given a computerized, 20-question, multiple-choice quiz about various aspects of the game they had been playing for the previous two hours. Some questions involved simple observation (e.g., whether the whale had an eye, and the approximate number of icebergs), while others asked about functional characteristics (e.g., whether 
the whale could move diagonally or cross the screen boundary). Somewhat surprisingly, the average performance on this quiz of 44 subjects from two experiments was relatively poor $(M=58.5 \%, S D=11.5 \%)$. Most subjects did not realize that the number of kayaks was constant or that they appeared at the same time and location during every game. Nearly half of the subjects did not realize that the iceberg clusters presented on the screen were the same on each of the 27 trials they had just completed. One positive effect of such apparent ignorance was that the subjects experienced the game as being much more random and uncertain than it actually was. A negative implication of their poor quiz performance was that they were apparently unable to identify many of the appropriate answers that should have been necessary for them to develop effective game strategies.

In another postgame task, the subjects were asked to rate the three priority conditions (plankton, equal, or kayak) in terms of their relative difficulty, complexity, and uncertainty. They consistently rated the plankton task as much easier, more simple, and more predictable than either the kayak or the equal-priority conditions. However, on average, the subjects did notice that the plankton task was somewhat more uncertain than it was complex and that the kayak task was more complex than it was uncertain. These subjective ratings were extremely consistent across experiments, as well as across subjects.

The subjective perspective also included subjects' verbal accounts of their own play. Because subjects came to view the game as a personal challenge, many of them spontaneously expressed their own assumptions about the game and about the actions needed to improve their performance. Initial experimenter impressions led to more systematic collection of verbal protocols during the experimental debriefing and, subsequently, to a short, multiple-choice instrument asking the subjects to rank order the effectiveness of six alternative strategies for each of the game tasks. The subjects had little trouble selecting appropriate rules for each task, and they expressed an equally high level of confidence in their strategic selections for each task.

An interesting discontinuity became obvious when results from this subjective analysis were compared with the previous objective statistical analysis of performance. The strategies that the subjects espoused for the plankton task showed nearly perfect correspondence to the actual objective rules derived from regression analysis of tabulated game behaviors. In contrast, however, the strategies that the subjects selected as being the most appropriate for accomplishing the kayak task showed no correspondence to the behaviors derived from objective analysis. For example, the single strategy most strongly endorsed by subjects ("don't eat the icebergs") showed a correlation with success on the kayak task of an insignificant .04. In contrast, "stay in the center portion of the screen" showed an objective correlation with kayak success of .47 , but, on average, it was not endorsed by subjects. Another rule ("turn and proceed directly away from the kayaks") showed a negative correlation of .54 with success, but received a moderately high positive endorse- ment from subjects (Porter, 1986). These results suggested that the rules that subjects were likely to employ consciously in accomplishing the plankton task would enhance their performance, but that the rules they were likely to rely upon in trying to talk their way through the kayak task might actually impede their performance.

\section{The Empirical Perspective}

The final perspective-namely, the empirical perspective-is that of the researcher. Unlike either the objective or the subjective perspective, the empirical perspective involves not only passive observation and description but also active involvement in introducing systematic external changes to the experimental situation. Before discussing the more traditional active experimental interventions, it is important first to provide an account of two general independent variables likely to be present in most experimental situations, and especially in games. These two variables consist of instructions and practice. The directions that preceded each experimental trial had huge effects on the subjects' performance. An advantage of the awarding of different priorities to the two tasks during different game trials is that it allowed a standard baseline of effect size against which to assess the effects of other variables. The average main effects of priority on both tasks were dramatic: the average effect size on plankton performance was 1.98 and 1.48 for the kayak task. The average effect of one hour's practice on the two tasks was also very significant (.67 for the plankton task and .70 for the kayak task; Porter, 1986). (Although regression analysis suggested that both tasks were learned at approximately the same rate, closer inspection of individual data showed distinct differences between the two tasks: performance on the plankton task showed slow, steady improvement for the first dozen trials and then tended to asymptote and remain relatively constant; for the kayak task, however, many individual subjects' data showed sharp and dramatic increases from one trial to the next, which is characteristic of insight learning. However, when data from all of the subjects were pooled, these dramatic increases in individual performance were obscured.) Together, these results suggest that the subjects controlled their behavior to conform to instructions across a broad range of experimental conditions, and that they appeared to improve steadily with practice.

A third important source of variability can lie in the differences in individual skill and motivation; this source of variance was controlled statistically. The performance of each subject across all trials and conditions was standardized (i.e., each subject's average performance on each performance parameter was 50 , with a standard deviation of 10 ). This allowed data to be combined meaningfully to explore the effects of different experimental treatments on all subjects' performance, and prevented those subjects with the most variable data from having an inordinate effect on the overall results (Wickens, Mountford, \& Schriener, 1981).

The original set of five experiments involved the introduction of six different concurrent tasks; only two, 
however, will be presented here. Both of these tasks required concurrent auditory/verbal activity designed to minimize their peripheral interference with game activities (Wickens, 1992). The first concurrent task required the subjects to retain random strings of 0,3 , or 5 phonemically distinct letters while playing the game. The imposition of this task interacted with the priority instructions to create significant disruption in the performance of the plankton task $[t(270)=-2.03, p<.05]$. In contrast, the same verbal concurrent task showed a slight but positive effect $[t(270)=+.35$, n.s.] on subjects' performance of the kayak task (Porter, 1991). The effect size of this intervention on the two tasks was -.29 for the plankton task and +.05 for the kayak task. Although these results are a predictable consequence of the preceding objective and subjective analyses of performance, they run counter to the widely assumed correspondence between task difficulty and susceptibility to disruption from a concurrent task (Kahneman, 1973; Norman \& Bobrow, 1975). These results were also contrary to the subjects' own expectations; most of them were relatively certain that their performance of the kayak task had suffered much more from the imposition of concurrent side tasks than had their performance of the plankton task.

A second experiment involved the introduction of a verbal concurrent task, first introduced by Baddeley (1966). This task required subjects to produce the numbers $1,2,3$, and 4 in random order. The task was made even more demanding than the original task by requiring the subjects to produce their numbers in time with a metronome operating at approximately 1 beat every $1.3 \mathrm{sec}$. The subjects' responses were immediately input to a simple program designed to detect repetitive patterns or nonrandom sequences. Not too surprisingly, this demanding concurrent task caused significant interference with both game tasks. However, the effects on the two tasks differed significantly after 30 min of intermittent practice. The effects on the simple, but uncertain, plankton task were direct and substantial $[t(324)=$ $-6.32, p<.05]$ and showed no sign of interacting with either practice or priority. Initially the disruption of the subjects' performance of the complex but certain kayak task was nearly identical; however, after $30 \mathrm{~min}$ of practice, the effects of this demanding side task completely disappeared. The interaction between the side-task interference with performance of the kayak task and practice was significantly positive $[t(324)=+2.40, p<.05$; Porter, 1991]. This result suggested that performance of the kayak task was "automated," despite the subjects' lack of explicit knowledge of the appropriate procedures.

\section{SUMMARY AND CONCLUSIONS}

Information from objective analyses of the task structure were compared with the players' subjective accounts. Discontinuities were used to develop alternative hypotheses regarding the existence of distinctive alternative modes of information processing and learning (Hayes \& Broadbent, 1988). Subsequent experiments tested these hypotheses against traditional hypotheses concerning task difficulty and side-task interference, as well as both subjects' and scientists' intuitive predictions of their relative effects on side tasks. Results from these experiments provided convergent support for Broadbent's (1977) notions concerning distinctive processing modes.

In a somewhat broader context, these activities provide an example of the utility of incorporating analyses from a variety of perspectives in order to better understand individual human behavior. Objective statistical analysis of the relationships between inputs and outputs were used to construct a logical path structure to explain successful game performance. The rules contained in this structure were then tested by constructing a computer simulation incorporating the rules derived from regression analysis. The subjects' verbal reports were also useful in better understanding game performance. Even a game of modest complexity is likely to create an illusion of uncertainty because subjects engaged in playing the game are likely to miss many substantive constant relationships as well as peripheral details. The striking discontinuity between subjects' explication of appropriate strategies for the accomplishment of the complex but certain kayak task suggested that their natural concurrent verbalization (i.e., self instruction) was probably not helpful. This observation, in turn, supported the development of counterintuitive hypotheses concerning sidetask interference and the development of automaticity.

Once the game is understood, it can be adapted to a wide variety of uses. Several students used the game to demonstrate an impressive interaction between individuals' competitiveness and the reward structure on performance (Porter, Bird, \& Wunder, 1990) and another modified the task to compare strategic consequences of voice and manual control systems (Thurber \& Porter, 1990). Knowing how computer games really work from an "inside" perspective and how subjects think they operate from the outside are both necessary prerequisites for developing appropriate empirical procedures. Without such complementary analyses, computer games are likely to remain outside the realm of traditional experimental methods. However, continued emphasis on multiple convergent analyses and empirical verification of resulting hypotheses is likely to render even the secrets of much grander and more substantive arcade games vulnerable to psychological inquiry.

\section{REFERENCES}

BADDELEY, A. D. (1966). Capacity for generating information by randomization. Quarterly Journal of Experimental Psychology, 18, 119-129.

Broadbent, D. E. (1971). Decision and stress. London: Academic Press. BroadBENT, D. E. (1977). Levels, hierarchies, and locus of control. Quarterly Journal of Experimental Psychology, 29, 181-201.

BROADBENT, D. E. (1986). The enterprise of performance. Quarterly Journal of Experimental Psychology, 38A, 151-162.

Broadbent, D. E., Fitzgerald, P., \& Broadbent, M. H. P. (1986). Implicit and explicit knowledge in the control of complex systems. British Journal of Psychology, 77, 33-50.

Cohen, A. R., Fink, S. L., Gadon, H., \& Willits, R. D. (1980). Effec- 
tive behavior in organizations: Learning from the interplay of cases. concepts, and student experiences. Homewood, IL: Irwin.

COHEN, J., \& COHEN, P. (1983). Applied multiple regression/correlation analysis for the behavioral sciences (2nd ed.). Hillsdale, $\mathrm{NJ}$ : Erlbaum.

CRAIK, K. J. W. (1943). The nature of explanation. London: Cambridge University Press.

ERICsson, K. A., \& Simon, H. A. (1984). Protocol analysis: Verbal reports as data. Cambridge, MA: MIT Press.

EYSENCK, M. W. (1984). A handbook of cognitive psychology. Hillsdale, NJ: Erlbaum.

GiBson, J. J. (1962). Observations on active touch. Psychological Review, 69, 477-491.

Hayes, N. A., \& Broadbent, D. E. (1988). Two modes of learning for interactive tasks. Cognition, 28, 249-276.

Hergenhahn, B. R., \& Olson, M. H. (1993). An introduction to theories of learning (4th ed.). Englewood Cliffs, NJ: Prentice-Hall.

Kahneman, D. (1973). Attention and effort. Englewood Cliffs, NJ: Prentice-Hall.

Mook, D. G. (1982). Psychological research: Strategy and tactics. New York: Harper \& Row.

Nie, N. H., Hull, C. H., Jenkins, J. G., Steinbrenner, K., \& Bent, D. H. (1975). Statistical package for the social sciences (2nd ed.). New York: McGraw-Hill.

Norman, D., \& BOBROw, D. (1975). On data-limited and resourcelimited processing. Journal of Cognitive Psychology, 7, 44-60.

Piaget, J. (1970). Genetic epistemology. (E. Duckworth, Trans.). New York: Columbia University Press. (Original work published 1969)

PORTER, D. B. (1986). A functional examination of intermediate cognitive processes. Unpublished doctoral dissertation, Oxford University.

PORTER, D. B. (1991). Computer games and cognitive process: Two tasks, two modes, too much? British Journal of Pswchologv, 82, 343357.

PorTer, D. B., Bird, M., \& WUNDER, A. (1990). Competition, cooperation, satisfaction and the performance of complex tasks among air force cadets. Current Psychologv Research \& Reviews, 9, 347-354.

Reason, J. T. (1984). Lapses of attention. In R. Parasuraman \& R. Davis (Eds.), Varieties of attention (pp. 82-107). New York: Academic Press.

SEARLE, J. (1980). Minds, brains, and programs. Behavioral \& Brain Sciences, 3, 417-457.

Thomas, J. C. (1974). An analysis of behavior in the hobbits and orcs problem. Cognitive Psychology, 6, 257-269.

Thurber, B. J., \& PorTer, D. B. (1990). Prediction of vocal performance using a complex computer game. In D. H. Lindsley (Ed.), Proceedings: Psychology in the Department of Defense-Twelfth Symposium (pp. 132-136). United States Air Force Academy, CO: Department of Behavioral Sciences and Leadership.

Watson, J. B. (1913). Psychology as a behaviorist views it. Psychological Review, 20, 158-170.

WERTHEIMER, M. (1959). Productive thinking. New York: Harper \& Row. WICKENS, C. D. (1992). Engineering psychology and human performance (2nd ed.). New York: HarperCollins.

Wickens, C. D., MountFord, S. J., \& SCHRIENER, W. (1981). Multiple resaurces, task hemispheric integrity and individual differences in time sharing. Human Factors, 23, 211-229.

WRIGHT, S. (1921). Correlation and causation. Journal of Agricultural Research, 20, 557-585.

(Manuscript received December 2, 1994; revision accepted for publication January 31,1995 .) 